Reflexivity and bracketing in sociological phenomenological research: researching the competitive swimming lifeworld

McNarry, Gareth; Allen-Collinson, Jacquelyn; Evans, Adam B.

Published in:

Qualitative Research in Sport, Exercise and Health

DOI:

10.1080/2159676X.2018.1506498

Publication date:

2019

Document version

Peer reviewed version

Citation for published version (APA):

McNarry, G., Allen-Collinson, J., \& Evans, A. B. (2019). Reflexivity and bracketing in sociological

phenomenological research: researching the competitive swimming lifeworld. Qualitative Research in Sport, Exercise and Health, 11(1), 138-151. https://doi.org/10.1080/2159676X.2018.1506498 
Authors' pre-publication copy - may contain typographical errors

Gareth McNarry, Jacquelyn Allen-Collinson \& Adam B Evans (2018): Reflexivity and bracketing in sociological phenomenological research: researching the competitive swimming lifeworld, Qualitative Research in Sport, Exercise and Health, Online early

DOI: $10.1080 / 2159676 X .2018 .1506498$

To link to this article: https://doi.org/10.1080/2159676X.2018.1506498

\section{Reflexivity and bracketing in sociological phenomenological research: researching the competitive swimming lifeworld}

Gareth McNarry, Jacquelyn Allen-Collinson \& Adam B Evans

CONTACT Gareth McNarry gmcnarry@lincoln.ac.uk Health Advancement Research Team (HART), School of Sport \& Exercise Science, University of Lincoln, Lincoln, UK 


\title{
Reflexivity and bracketing in sociological phenomenological research: researching the competitive swimming lifeworld
}

\begin{abstract}
In this article, following on from earlier debates in the journal regarding the 'thorny issue' of epochē and bracketing in sociological phenomenological research, we consider more generally the challenges of engaging in reflexivity and bracketing when undertaking ethnographic 'insider' research, or research in familiar settings. We ground our discussion and illustrate some of the key challenges by drawing on the experience of undertaking this research approach with a group of competitive swimmers, who were participating in a British university performance swimming programme at the time of the doctoral study. The primary researcher was highly familiar with the phenomenon of competitive swimming, having been both a competitive swimmer and swimming coach. Some of the key elements of a sociological phenomenological approach to studying physical-cultural embodiment are first delineated, before addressing the considerable challenges of engaging in sustained reflexivity and bracketing, using the swimming research for illustrative purposes. We suggest some practical ways in which researchers in sport and physical cultures might approach epochē and bracketing in ethnographic 'insider' research.
\end{abstract}

Keywords: sociological phenomenology; competitive swimming; insider research; epochē; bracketing.

\section{Introduction}

Phenomenology, the study of phenomena or things as they appear to our conscious mind, has only relatively recently been adopted to any great extent by psychological and sociological researchers in studies of sport, exercise, and physical cultures (Kerry and Armour, 2000; Nesti, 2004; Allen-Collinson, 2009, 2011; Lund et al., 2012; Ravn and Høffding, 2016; Parviainen and Aromaa, 2017), and has been found powerful in portraying and analysing the richness of lived-body experiences in these domains. Since de Beauvoir's (1972) pioneering work in existentialist feminism in the 1940s, feminist phenomenologists have been amongst those who have drawn upon phenomenology as both a theoretical and methodological framework to address women's sporting, exercise and physical-cultural embodiment (e.g., Young, 1980; Chisholm, 2008).

We focus here upon a sociological form of phenomenology (Allen-Collinson, 2011), as employed in an ethnographic research project on competitive swimmers involved in a British university performance swimming programme. To date, this research has included two intense, five-week long immersions in the field, where the principal researcher adopted the role of a voluntary assistant coach, affording him excellent opportunities to observe the 
swimmers in action in and around the pool. Having been both a competitive swimmer and a swimming coach himself, this was a role with which the researcher was highly familiar, rendering him on many dimensions a physical-cultural insider. Whilst this researcher role brought many advantages in terms of securing access to the field site, including many of its back-stage regions (Goffman, 1959), and familiarity with the lifeworld and embodied experiences of competitive swimmers (see also, McMahon et al., 2017), it also brought considerable challenges in terms of researcher reflexivity in familiar settings. Here, our aim is to contribute to debates regarding reflexivity in sociological phenomenological research on sport and physical cultures, and in particular to discussions surrounding what has been termed the 'thorny issue' of bracketing and engaging in the phenomenological epoche (AllenCollinson, 2011). This latter is the process by which researchers seek to 'stand aside from' their extant assumptions and presuppositions surrounding phenomena under investigation. We use the example of the research on swimming for illustrative purposes, in order to 'ground' the discussion.

We portray some of the substantial challenges confronting Author 1, Gareth (hereafter named ' $G$ '), as the primary researcher on the swimming research project, in attempting epochē when researching a sporting lifeworld with which he was very familiar. As Howe (2018, p. 682) notes, the embodied sensuous ethnographer has a role to play in shaping the lifeworld under investigation, but, 'It is difficult if not impossible to know how the involvement of the ethnographer shapes the social environment'. Such shaping and influencing of the lifeworlds we study is a central issue for reflexive and sensory ethnographers (Sparkes, 2017). Swimming provides a strong site for investigating the sensorium as lived by both participants and researchers, as we describe below in relation to instances of somatic awareness and 'intense embodiment' (Allen-Collinson and Owton, 2015) in the aquatic environment. First, we provide a brief overview of the form of phenomenological sociology we utilise, which also draws on the work of the existential 
phenomenologist, Maurice Merleau-Ponty, and the social phenomenology of Alfred Schütz who combined sociological and phenomenological thinking.

\section{Researching the lifeworld: sociological phenomenology}

Whilst there is wide diversity between different forms or strands of phenomenology, the phenomenological position in general holds to an ontological and epistemological 'third way'; that is whilst the existence of any 'external' world is not denied, its nature and our ways of knowing it are construed as problematic. Mind, body, and world are considered fundamentally intertwined, braided, inter-relating and reciprocally influencing. Indeed, so closely interwoven are mind-body-world that Merleau-Ponty (1969) in his later, unfinished work, recasts our being-in-the-world as 'chair' or flesh-of-the-world, thus signalling the continuity of the 'fabric' of body-with-world. Ontologically, for phenomenologists, phenomena are not just things 'out there' in the world, separate from our human consciousness and experience. Rather, all form part of our incarnate subjectivity. The nexus of mind-body-environment means we are entwined (and enfleshed) with the world. Furthermore, the phenomenological conceptualisation of the Lebenswelt or lifeworld highlights how, in the general routines of life, there is a tacit, taken-for-grantedness about this world of everyday life. The lifeworld is generally hidden to us as a phenomenon; we accept it as simply there, an unquestioning acceptance known in phenomenology as the natural attitude. Problematising and subjecting the lifeworld to scrutiny and questioning is precisely what we seek to do via engagement in the phenomenological epochē or bracketing, as we explain below.

Despite existential phenomenology's emphasis on the environmental situatedness of the body-mind, it has at times been criticised for a lack of analytic attention to socio-cultural and structural influences on embodiment and lived-body experience. Similarly, it has been accused of neglecting 'difference' generated by key sociological variables such as gender, 
class, age, ethnicity, degrees of dis/ability, and so on. Whilst there is insufficient scope within the current article to engage in debate regarding the different traditions of philosophical phenomenology, for our present purposes we simply wish to note that forms of more social and 'sociologised' phenomenology or phenomenologically-shaped sociology explicitly acknowledge and theorise the structurally-influenced, historically-specific and culturallysituated nature of experience (Allen-Collinson, 2009, 2011), including sporting and physicalcultural experience. In relation to gender, for example, feminist phenomenology has been strong in highlighting the specificity rather than universality of lived experience of phenomena (e.g., Young, 1998; Fisher and Embree, 2000; Chisholm, 2008).

In terms of sociological linkages with phenomenology, many Husserlian phenomenological insights were taken up and developed within sociology by Schütz (1967) whose sociological imagination was sparked by the concept of the intersubjective lifeworld. In synthesizing phenomenological ideas with a sociological interest in social action, Schütz (1967) emphasized the need for investigating lifeworlds as firmly embedded within socialstructural contexts. This sociologised lens encourages the identification and analysis of the impact of social-structural forces upon even the most deeply embodied, sensory, and 'carnal' (Crossley, 1995) of experiences. Such a theoretical linkage addresses the understandable concerns of many sociologists regarding the lack of recognition accorded to social-structural factors in more traditional forms of phenomenology, including the concerns of feminist sociologists and those working from a 'new materialist' perspective (for example, Fullagar, 2017).

As Shilling (2017) notes, sociological researchers have drawn on Merleau-Ponty's phenomenological work to understand how embodied consciousness is demonstrated, learnt and re-learnt within occupational, sporting and other settings (see also Kupers, 2005; Hockey and Allen-Collinson, 2009; Allen-Collinson and Hockey, 2011). Of direct relevance to our 
work, and employing phenomenologically-inspired insights, Leder (1990) portrays how our intentionality shifts to our body, which 'dys-appears', sometimes abruptly, when discomfort, pain or other intense sensations suddenly disrupt the natural attitude and everyday state of corporeal 'disappearance' from the forefront of conscious mind. For example, in the aquatic lifeworlds of competitive swimmers, the body might 'dys-appear', as a result of intense fatigue, exhaustion, pain, discomfort, and cold, so that the (swimming) body is suddenly encountered as 'that which stands in the way, an obstinate force interfering with our projects' (Leder, 1990, p. 84). Below we seek briefly to 'give a feel for' the world of competitive swimming, which $\mathrm{G}$ was studying, before delineating the actual research project and the challenges of engaging in bracketing when researching a physical-cultural domain with which one is very familiar. First, though, we consider epochē/bracketing and reflexivity in general.

\section{Epochē/bracketing and reflexivity}

The purpose of much phenomenological research is to provide rich, detailed and textured descriptions of phenomena as experienced by participants in actual concrete contexts, without undue emphasis on the theorisation of these experiences. For example, Nesti (2004, p. 41), describes how: 'Phenomenology requires the researcher and the subject ${ }^{1}$ to maintain their penetrating gaze at the phenomenon under consideration, without moving off target and starting to try and account for its existence...'. In order to focus this penetrating gaze, descriptive phenomenologists follow Husserl's $(1983,1999)$ exhortation 'to return to the things themselves', in an effort to suspend as far as possible the researcher's own 'natural attitude'; that is, her or his preconceptions, presuppositions, attitudes toward, and interpretations of the phenomenon, for example, competitive swimming. This attitudinal suspension is sought via a process of epochē and then reduction in order first to address the

\footnotetext{
1 'participant' would be the more usual term in sociological phenomenology
} 
phenomenon with a fresh eye (and via other sensory modes) and then reduce it to its essences, or key characteristics. We should note here that whilst many phenomenologists acknowledge different nuances of meaning between the concepts of epochē, bracketing and reduction, in practice, the terms are often used synonymously. Furthermore, Husserl himself is considered by some (see for example, Stewart and Mickunas, 1990, p. 27) to employ the terms interchangeably to refer in general to the 'change in attitude necessary for philosophical inquiry'.

Via the process of epochē (derived from the Greek: to stand aside from, or keep a distance from), as noted above, phenomenological researchers aim temporarily to set aside their tacit assumptions about a phenomenon, to approach it freshly, without prejudgment, seeking to slice through the layers of received knowledge, ideas and assumptions that envelop it in both everyday and 'scientific' thinking. Following the epochē, phenomenological researchers seek to identify via eidetic reduction and variation the essential structures or characteristics of the phenomenon, its essence or eidos, the thing(s) without which the phenomenon would cease to be recognisable as that particular phenomenon. For us as sociological phenomenologists, the identification of such essences is not so much about trying to locate invariant structures of consciousness, but more akin to seeking generalities in the phenomenon, often across a range of different participants' accounts. We are in full agreement with Merleau-Ponty (1969), who highlights the impossibility of any complete reduction, and posits that the very incompleteness of the process is not an obstacle to the reduction, but is the reduction itself (see also, Smith 2005). As phenomenologically-inspired sociologists, we are quick to admit that attaining full epochē, so that we can somehow 'stand aside from' our own socio-cultural situatedness, is quite simply an impossibility - in research as in everyday life. As sociological researchers, our theories and concepts are already in mind, socialised into us as academics; our ideas, assumptions, meanings, interpretations are always inevitably there, including in the interpretation of our ethnographic field and 
observations, so that these can never be neutral, 'unknowing' or value-free. We can though make best efforts to 'stand back' and maintain a critical perspective and analytic distance on these, being reflexive and self-critical towards our assumptions and preconceptions.

Engagement with reflexive practice is increasingly crucial across the social sciences. The acknowledgment that the researcher cannot be detached from the research process, but is part of it, is an important one, which fundamentally challenges notions that research is presented as a 'view from nowhere' (Hesse-Biber, 2016, p.19). Researchers are humans, socialised into particular socio-cultural, socio-psychological and socio-economic ways of being. They hold values and 'biases' that are products of such socialisation. Furthermore, meaning is interpreted through such lenses. Decisions regarding research approach, paradigmatic standpoint, adoption of a theoretical lens (and when), and methodological design are all products of the relative strengths, weaknesses, knowledge, ways of knowing, and biographical experiences of the researching subject. As Sparkes and Smith (2014, p. 9) suggest:

...we conduct inquiry via a particular paradigm because it embodies assumptions about the world that we believe in and supports the values that we hold dear. And, because we hold these assumptions and values we conduct inquiry according to the precepts of that paradigm.

Researchers are also relational. They are situated both within the power-hierarchies and norms of their research field, and in relation to the people who are the object of their study, and the readers of their research reports and outputs. Put simply, research is not detached from a complex and changing social system; it is a product of that system and the individuals who constitute it. All is already interpretation (Dreyfus and Rabinow, 1982). Across the social sciences more generally, therefore, reflexivity is considered a holistic process that is enacted across all stages of the research process, from problem formulation, 
via management of the research process and the relationship between researchers and participants (often in 'real-time') to data analysis and writing (Hesse-Biber and Piatelli, 2012; Buscatto, 2016). The reflexive gaze incorporates appreciation of both the external power relations surrounding research, and also shifts internally towards the researcher. Reflection is a communal process and requires relation to the structural, political and cultural environments of the researcher, the participants, the nature of the study, research process and results (Hesse-Biber and Piatelli, 2012; Buscatto, 2016). Engagement in such reflexive praxis therefore raises awareness of the way in which knowledge is subject to social conditions, location, and biography of the observer and the observed (Mann and Kelly, 1997), the better that a researcher might explicate their own position.

There are myriad ways in which such reflexive practice could be employed, and specific guidelines are sparse. Frequently, reflexive practice is allied to a particular ontological, epistemological or theoretical tradition (e.g. Hesse-Biber and Piatelli, 2012; Allen-Collinson, 2013). And yet, descriptive accounts of this process are relatively rare. Many scientific publications, particularly in the natural sciences, have neither the requirement, nor allocated space, to discuss such processes. More often than not, it is just assumed that rigorous 'scientific practice' has been followed. Here, therefore, we focus explicitly on the reflexive process in which we engaged specifically for the sociological phenomenological project on competitive swimmers, including best efforts to achieve (at least some degree of) epochē/bracketing. Before portraying some of the ways in which 'reflexive bracketing' (Ahern, 1999) was undertaken, we first portray the research itself and the Lebenswelt of the competitive swimmers studied, in order to 'ground' discussions regarding reflexivity and bracketing. 


\section{Researching the lifeworld of competitive swimming: insider perspectives}

Swimming is one of the main sports in the modern Olympic era, where athletes compete in events of varied distances $(50 \mathrm{~m}, 100 \mathrm{~m}, 200 \mathrm{~m}, 400 \mathrm{~m}, 800 \mathrm{~m}, 1500 \mathrm{~m}$ and $10 \mathrm{~km})$, using the four designated racing strokes of butterfly, backstroke, breaststroke, and frontcrawl, or all four together during individual medley events. In addition to these individual events, swimmers can also participate in the $400 \mathrm{~m}$ or $800 \mathrm{~m}$ freestyle or $400 \mathrm{~m}$ medley relay events that involve teams of 4 swimmers covering $100 \mathrm{~m}$ or $200 \mathrm{~m}$ each. These events can either be 'same-sex' teams ( 4 male or 4 female swimmers) or mixed teams ( 2 male and 2 female swimmers per team) depending on the event. All such events take place under the rules and regulations of the international governing body of competitive swimming, the Federation Internationale de Natation Amateur (FINA). Currently within Great Britain (England, Scotland, Wales) there are over 80,000 registered competitive swimmers (category 2 members), representing approximately 1500 swimming clubs. Swimmers registered in this category will have the opportunity to swim competitively at local, county, regional, national or international levels, including able-bodied, para, and masters' events.

The training involved at these levels varies greatly, with some swimmers completing a couple of sessions per week whilst others train twice daily, covering anywhere from $25 \mathrm{~km}$ to over $100 \mathrm{~km}$ in the pool per week. This is widely accepted within swimming as being the norm, with this intense training regime being adopted early in a swimmer's career, usually during early adolescence. In addition to the volume of training in the pool, as a swimmer progresses into her/his late teens, s/he will often begin to supplement pool work with gymbased activities that can, and often do, include weight-training, circuits, yoga, Pilates and 'spin' classes. The time and energy commitment required, together with the intensity of training, makes this an interesting physical-cultural lifeworld to study, but one that to date remains sociologically under-explored. 
As with most phenomenologically-inspired research on sport and physical cultures, a key purpose of the project overall was to generate rich, detailed descriptions of the lifeworld under investigation. Ethical approval for the ethnographic study was obtained from the principal researcher's University department. Throughout the project, we sought to operate an 'ethic of care' (Plummer, 2001) particularly in G's empathic thinking toward and interactions with the swimmers, with many of whom he developed relationships akin in some ways to friendships (see Owton and Allen-Collinson, 2014, for an extended discussion), whilst also recognising the requirements of his researcher role and the limits of empathy. As qualitative researchers have argued (for example, Frank, 2005; Smith et al., 2009), empathy is important in this form of research, and striving for empathy is a means by which we can enhance our understanding of others, engendering trust and rapport, and generating deeper knowledge of the human condition generally. It is, however, also important to acknowledge the limits of empathy, as Frank (2005) has pointed out, especially if empathy risks turning into projection of thoughts and feelings on to others, and thus results, however unintentionally, in 'finalising' our participants rather than maintaining a dialogue with them (Smith et al., 2009).

We drew on Giorgi's (1997) phenomenological approach to data collection and analysis. This approach involves the following stages: (1) collecting concrete descriptions from the participants' 'insider' perspective; (2) the adoption of the phenomenological attitude via epochē/bracketing (which we explore in more detail below); (3) initial impressionistic readings of the assembled descriptions, to gain a feel for the overall data set; (4) in-depth rereading of these descriptions as part of a process of data immersion, to identify key themes and sub-themes; and (5) the production of general statements of the essential patterns or structure(s) of the experiences. In order to generate the requisite descriptions of concrete activities involved in competitive swimming, an ethnographic research design was 
employed, which drew upon overt participant observation, and also interviews with swimmers based in a senior performance programme at a British University.

G collected data over two intense, five-week long immersions in the field as part of a doctoral research project. During this time, and having explained the research purpose, processes and potential publication of findings in advance to all participants (swimmers, coaches, sports science support staff), G adopted the role of a voluntary coaching assistant, providing support to both the director of swimming and head swimming coach. This afforded him opportunities to observe the swimmers in action in and around the pool. Having been both a competitive swimmer and a swimming coach himself, this was a role with which $G$ was very familiar, rendering him what has been termed a cultural insider, and a 'cultured insider' (Wheaton, 2002; Evers, 2006). Although this level of active involvement offered G a strong position from which to gain in-depth information and insights, as Allen-Collinson (2013) notes in relation to insider researchers:

...it is debatable whether anyone can ever be deemed a complete member of any culture, subculture or social group...rather, it might be more accurate to posit that there are degrees of insiderness and outsiderness, which change over time, place and social context (p. 287).

With this in mind, G was aware that although his role was as a voluntary member of the coaching team, his insider/outsider status would be very much in flux throughout the project, with each position bringing with it specific possibilities, challenges and limitations (Thorpe and Olive, 2016). Maintaining a balance proved increasingly difficult as time went on. During initial observations, $G$ was free to walk the 'deck' (the tiled area around a swimming pool) and build relationships with the coaches, swimmers and other support staff. During this time, undertaking observations and making notes was relatively straightforward. As time 
progressed, however, G's coaching experience and skills were called upon more frequently, as he was asked to provide advice to coaches and swimmers on various matters, incuding technique, planning, and disciplinary matters, and to help coaches out with specific groups during particularly busy sessions. This eventually led to $G$ even being asked to cover complete sessions when the coaches were away at international events. In these situations the researcher/voluntary coaching assistant role balance was constantly in flux, and taking observational field notes became more challenging, sometimes impossible. At one point, this role tension even drew comment from a former coach, who wondered how $G$ was still managing to undertake the academic research as well as the coaching work.

In total, 90 training sessions, both in the pool and 'on land' (in the gym and the poolside land-conditioning room) were observed, lasting between 60 and 150 minutes. Notes were taken vis-a-vis the timings and type of training undertaken, and also more specifically on the swimmers' actions, expressions, behaviours and social interactions. These observations were supplemented by interviews for which participants were opportunistically sampled. In total, 19 interviews were conducted with 12 male and 7 female athletes, aged 18 to 22, who had competed at a minimum of British Championship level. To compete at this level requires a high level of commitment to, and familiarity with the sport, and thus helped ensure that participants were in a position to provide rich, in-depth descriptions of this particular lifeworld. The participant cohort included athletes who had also competed at the European Youth Olympic Festival, European Juniors, European Games, Commonwealth Youth Games, Commonwealth Games and World Championship level. All participants interviewed were white and of either British or Irish ethnicity, and all were considered able bodied swimmers under Fédération Internationale de Natation (FINA) rules. Although each of the swimmers came from a different part of the UK and/or Ireland, they were all students registered on either full- or part-time programmes of study and competed in a variety of 
Olympic events. No open water or para-swimmers were interviewed, although both kinds of swimmers were present during observations.

Prior to the interviews, informed consent was obtained from each participant. Interviews lasted between 60 and 90 minutes and were digitally recorded on a Dictaphone. Each interview took place at the athletes' training venue, either in a meeting room or in the athletes' lounge, helping to create a relaxed atmosphere for participants to feel at ease. The interviews were semi-structured in nature, drawing influence from Kvale and Brinkmann's (2009) lifeworld interview design, which seeks to understand themes of the lived, everyday world from the participant's perspective. The research utilised a very broad interview guide, as the key purpose was to facilitate an open and conversational format, allowing participants to portray their experiences in-depth and, importantly, in their own terminology. Each interview began with $\mathrm{G}$ asking the participant to describe their personal swimming journey, with subsequent general questions relating to, for example: their current training schedule and practices, and embodied and sensory experiences of swimming. Initial interviews were conducted during the first 'field immersion', with a follow-up meeting taking place during the second immersion, at which point $\mathrm{G}$ was able to ask additional questions, arising from the fieldwork observations, or to gain further clarification on points already emergent from the analysis. For example, having noted that music was played during some of the training sessions, $G$ asked the swimmers if this influenced them in anyway, and whether they sang along to the music - out loud or in their heads.

Prior to, and during data collection, and commensurate with the phenomenologicalsociological approach adopted, G participated in a variety of bracketing and reflexivityenhancing processes that are portrayed below, in order to address the need, identified by Allen-Collinson (2011), for phenomenologically-inspired researchers to describe how they actually approach the challenge of bracketing. 


\section{Approaches to bracketing in a familiar setting}

As noted above, G's position as a 'cultured insider' (Wheaton, 2002; Evers, 2006) in the lifeworld of UK elite swimming provided a level of familiarity with competitive swimming at this level. On the one hand, such positioning helped him gain access to the research site and its lifeworld inhabitants; on the other, it did raise considerable challenges in engaging with bracketing. This, as Ashworth (1999, p.708) notes, involves making a determined effort 'to set aside theories, research propositions, ready-made interpretations, etc., in order to reveal engaged lived experiences'. But this is no easily-achieved feat for researchers. As we emphasize above, as sociologists who engage in phenomenologically-inspired research, we are highly cognisant that we can never completely stand outside of our own socio-cultural and socio-structural situatedness. We can, however, seek to 'stand back' and maintain a critical perspective on our theories, assumptions and familiar ways of thinking, doing and interpreting, making our best efforts to be reflexive, and self-critical towards our assumptions and preconceptions. In the following sections, we provide examples of how the bracketing process was undertaken before and during the swimming research project. We should emphasize that these examples are provided as suggestions that others may wish to consider; we are not proposing some rigid formulation for undertaking bracketing, or arguing for some definitive research technique. What we are charting here are the steps that $\mathrm{G}$ took in order to challenge some of his own personal physical-cultural knowledge about, and experiences of, competitive swimming and coaching, in an effort to illustrate some ways in which we can attempt to engage with the process of 'reflexive bracketing' (Ahern, 1999). The purpose here was to allow $\mathrm{G}$ to look upon the highly familiar swimming Lebenswelt as strange, 'exotic', puzzling, and replete with wonder.

This task was assisted early on in the project due to the differing degrees of insiderness within the research team. One of the research team members, Adam, was also an ex-competitive swimmer who had (long ago) trained in the self-same research setting as a 
squad member, although he had not competed in over a decade. He had also only coached on a voluntary basis on a handful of occasions, and his recollections of competitive swimming were centred more upon those of only the 'swimmer' role. Nevertheless, memories centring upon the experience of the swimming lifeworld, including heavy training workloads, periodisation, the sensory elements of being in the pool and the 'magnified moments' (Hochschild, 2003) of training and competing were still felt on a highly evocative level. Discussions within the team 'brought back' many of these memories for him, whilst his insider knowledge of the language and meanings associated with competitive swimming allowed him to act as a critical sounding board for G. Moreover, as a critical sociologist who had previously conducted research upon several non-competitive groups' subjective experiences of swimming (Evans and Allen-Collinson, 2016; Evans et al., 2017), he had been considering ways to study such experiences for a number of years and could draw on experience of the ways in which other groups described their experiences.

Our discussions were complemented by the other member of the team [to be named post-review], who was a complete outsider to the swimming lifeworld and had, since her twenties, very little experience of swimming at all. This placed her in a good position to pose 'naïve' questions to her two swimming-experienced research colleagues, whose vivid portrayals of swimming embodiment and training regimes piqued her phenomenological interest and curiosity. As an inhabitant of a very different physical-cultural lifeworld, she did, however, have experience of endurance training. Comparisons between her sporting lifeworld and that of performance swimming not only generated interesting discussions, but also helped challenge some of our tacit and taken-for-granted assumptions regarding both lifeworlds. In addition to the above 'bracketing' discussions, and prior to entering the field, $\mathrm{G}$ undertook what we have termed automethodological self-elicited reflections on his experiences of the swimming lifeworld. Having been out of performance swimming (as an athlete) for 14 years, $G$ 'returned to the water' to undertake a swim session and post-swim 
reflection. This allowed him the opportunity to reconnect with his swimming self and to contrast his present self and embodied swimming capabilities with those of his past 'former gloried self' (Adler and Adler, 1989). The following extracts from G's reflective notes evidence the strangeness of the sensations encountered during his return to the pool, where the body and specific body-parts 'dys-appeared' (Leder, 1990), but also highlight the unexpected pleasures of somatic awareness and 'intense embodiment' (Allen-Collinson and Owton, 2015):

I enter the last $15 \mathrm{~m}$ of the $50 \mathrm{~m}$, and I can feel my hands starting to ache. Muscles have been working at their maximum capacity for $35 \mathrm{~m}$ and the tingling starts in the tips of my fingers. It's like lots of little pins being stuck into my skin and its starting to spread...I fully expected that perhaps my triceps or shoulders would tighten but they feel ok. This is strange to me.

[As I finish the 50] I become overtly aware of my beating heart and gasping breaths. I find the sensations oddly pleasurable and discomforting at the same time. Pleasurable due to feeling alive, feeling my heart pulsing fast...knowing that freshly oxygenated blood is being moved around my body... but also, I feel discomforted. I don't consider myself to be an unfit or unhealthy individual, yet here I am after 50m of fast swimming, gasping for air and hanging on the end of the pool like I've just completed the most gruelling training set ever. It's frustrating because these things used to come so easily [and] here I am feeling drained after only 50m.

These extracts highlight that G's present-day corporeal experiences 'mismatched' those of his former 'gloried' swimming self in terms of what were considered 'normal' and 
anticipated sensations. This greatly assisted $\mathrm{G}$ in identifying his pre-existing assumptions regarding 'normal' swimming-body sensations, and also brought to conscious mind some of his own technical know-how or techné (Kosma and Buchanan, 2018):

...for someone who was never a breaststroke swimmer, I actually feel good. My mind is suddenly full of images and memories of working with some of my former swimmers... on their technique and...I start to focus on some of those technique points.

Armed with this refreshed embodied knowledge, $G$ utilised some key swim coaching texts, old training logs and notes, to stimulate reflection on his own assumptions and preconceptions of swimming and swim coaching. He then proceeded to record his reflections via both video- and audio-recording software. Initially, the recordings were intended only to be via video, but due to some technical difficulties where the video recording software crashed, it became necessary to utilise both video and audio to ensure at least one mode recorded in full. These reflections were deliberately kept 'open' and wide-ranging, with G allowing his thoughts and comments to wander, often returning to previous lines of thinking as new or other information came to mind. This process was undertaken on two separate occasions and the general topics of self-discussion included: 1) reflections on his career as a swimmer and how these experiences had shaped his coaching style; 2) thoughts on each of the swimming strokes and technical points; 3) periodisation (the division of the year into training cycles) and planning for different swimming events, and; 4) experiences of working with age-group, youth and senior swimmers, including successes, mistakes, and what he would do differently if given the opportunity to return to full-time coaching.

In addition to the two occasions of in-depth, elicited self-reflection on the elements portrayed above, $\mathrm{G}$ also made sustained efforts throughout the data collection period to 
enhance reflexivity. He conducted further video- and audio-recordings to reflect on what had been witnessed or experienced each week and how he might have influenced the ethnographic field. These recordings, together with personal reflective notes recorded as an integral part of field notes, added another layer of data collection. Furthermore, to help reflect on each interview in a systematic way, after it was completed $\mathrm{G}$ used a structured pro-forma to record his thinking about: 1) the relationship he was developing with the participant; 2) his responses to her/his account; 3) how the participant reacted to the questions posed; 4) how $\mathrm{G}$ responded to her/his answers, and; 5) anything that needed to be changed, clarified of further developed for subsequent interviews.

In addition to these recordings and interview reflections, $G$ also engaged with three further bracketing practices: (1) discussions with other insiders and non-insiders to the swimming life-world, both male and female, including other coaches, swimming support staff, supervisors (one of whom was a former competitive swimmer, and one a nonswimmer), PhD students and academics; (2) attending coaching workshops and research seminars, both swimming and non-swimming related and; (3) reading other ethnographic, phenomenologically-contoured and/or sensory accounts of different sporting and physical cultures, to compare and contrast these accounts with his own knowledge and experience of swimming. For example, he read accounts of mixed martial arts (Vaittinen, 2014; Spencer, 2015), bouldering (Hughes, 2016) and parkour (Clegg and Butryn, 2012).

In relation to points one and two above, the opportunity to interact with other swimming and non-swimming colleagues, friends and family, generated ideas that had not been considered during the initial self-elicited reflections. For example, on attending a phenomenology and qualitative research methods course, one of the speakers mentioned the difference between swimming in a short-course pool versus a long-course pool. This provided a key example of something that was so familiar to G, constituting part of his Lebenswelt, that it had been missed from his own reflections. Additionally, whilst attending 
a swimming coaches' workshop toward the end of his second fieldwork immersion, some of the ideas presented fundamentally challenged G's assumptions (gained previously from other coaches, coach education courses, workshops and texts) in regard to how much and what types of training were appropriate for age-group and youth athletes. Subsequent discussions with the programme coaches over the days following also continued to challenge G's thinking, not only in relation to age-group and youth swimmers, but also regarding seniors, and the type of athletes the programme should be targeting to recruit. Similarly, G's nonswimming friends, who coach in other sports, expressed surprise, even shock, at the volume of work and intensity of training practices undertaken by swimmers, questioning whether such methods were actually healthy and/or necessary for performance; a fundamental challenge to long-held beliefs and practices within the lifeworld of competitive swimming.

These bracketing practices, whilst presented here separately, in effect all worked together synergistically throughout the research project, when $\mathrm{G}$ was both in the field/pool and out of it.

\section{Summary - and towards a conclusion}

In this article, we have considered some of the challenges facing the sociologicalphenomenological researcher who undertakes insider research into a phenomenon with which s/he is 'vulgarly competent' (Garfinkel, 2002; emphasis in original). For the challenges of reflexivity and the phenomenological epochē are particularly acute for the insider researcher, who, to challenge preconceptions and sharpen the observational and analytical focus must also intensify her/his reflexivity when investigating a familiar physicalcultural Lebenswelt. As has been noted previously (Allen-Collinson, 2011), rarely do researchers actually describe in detail exactly how they have approached and attempted bracketing. Here, we have explicated some of the processes in which we engaged, in order 
to heighten reflexivity, including in relation to embedded, somatically sedimented knowledge and ways of knowing in competitive swimming and swim coaching.

These processes involved initial detailed discussions between the authors during early planning stages of the project, in order to challenge prior assumptions and understandings of the swimming lifeworld. $G$ then conducted a series of self-elicited reflections including a 'return to the water' that allowed him to reconnect with his 'former gloried' swimming self, bringing to the fore assumptions regarding sensations experienced by the swimming 'habitbody' (Merleau-Ponty, 2001; see also, Purser, 2018). With this knowledge at hand, G then employed various swimming and non-swimming texts further to stimulate and then record self-reflections about his own swimming and coaching careers, including the four swimming strokes and their technical points, as well as experience of periodisation and planning. Further reflexive recordings were conducted during data collection, alongside post-interview reflections. In addition to these recordings and reflections, $G$ also engaged in three further bracketing practices: discussions with both insiders and non-insiders to the swimming lifeworld, attending coaching workshops and research seminars, and the reading of other phenomenological and/or sensory ethnographic accounts. All these processes were intertwined and interrelated throughout the project.

So, it remains for us to reflect on what was achieved via these bracketing and reflexivity-enhancing processes. In undertaking the above steps, $\mathrm{G}$ felt able to recognise, acknowledge and seek to manage some of the role tensions occasioned by his complex positionality within the research setting. G's multiple perspectives, generated by inhabiting and moving between three roles (of swimmer, swimming coach and researcher), provided him with several advantages and disadvantages, and required careful reflection and management throughout the research period. G's pre-fieldwork discussions and reflections allowed him to enter the research context having identified and considered some of his preexisting assumptions and presuppositions as a coach, and upon the methods required for him 
to encourage the swimmers to share with him their embodied experiences, in their emic terms. Concurrently, G's coaching perspective accorded him privileged access to the competitive swimming lifeworld from a more 'insider' perspective than might otherwise have been possible, and also acted as an analytical fulcrum around which he could conceptualise and analyse the swimmers' experiences. As both swimmer and coach, G 'holds' the lived experience, swimming sensorium, embodied memories, and technical language with which to relate closely to those in the competitive swimming Lebenswelt. Engaging in the phenomenological epochē and undertaking the initial bracketing discussions and reflections allowed him to 'step aside' to some degree from this 'known' lifeworld, in order to make the familiar strange and problematic, and to subject it to scrutiny and questioning.

Subsequently, as G's time in the performance programme progressed, and the coaches placed growing trust in him, $G$ found himself pulled more towards the coaching role. Increasingly, he became seen as a resource and trusted member of the swimming programme, by both the other coaches and the swimmers. At this point in the research process, further engagement in bracketing practices and critical reflection became crucial to maintaining some balance between his researcher and coaching roles. For example, reflection on the quality of his observational notes, which he found were less detailed and rich during intense periods of coaching activity, enabled G consciously to take a 'step back', to remember and reassess the aims and objectives of the research, and to shift the balance more firmly back toward his researcher role. Such fluctuations in position presented some procedural dilemmas, however, and $\mathrm{G}$ had to ask to be excluded from coaching a specific group at some points during the fieldwork, in order to give him the time and space to fulfil his researcher role. His lived experience as a swimmer similarly created role tensions in the interview setting. On one hand, his embodied knowledge engendered a level of commonality with the swimmers, facilitating rapport and generating rich, detailed descriptions of embodied 
experience. On the other hand, on some occasions, interviewees seemed somewhat bemused when $\mathrm{G}$ asked them to identify and describe experiences, given their awareness that he was already familiar with such experiences. In these situations, G sought to reaffirm his researcher role, asking the swimmers to imagine that he was an outsider to the swimming lifeworld, in order to try and elicit deeper, more evocative descriptions.

As is common with much physical-cultural insider research (e.g. Atkinson, 2017; McMahon et al., 2017; Allen-Collinson et al., 2018), G's insider experience and perspectives provided significant advantages with regard to shared inhabitance of the lifeworld of those he was researching. Such long-standing and deeply embodied experience, however, also inevitably raises challenges vis-à-vis engaging in the phenomenological epochē, which we readily acknowledge is impossible to achieve fully. Nevertheless, it is a worthwhile endeavour to seek to problematise the tacit and taken-for-granted lifeworlds that we all inhabit, to hold these up to research scrutiny. Our intention here is not to propose a definitive set of research practices for others to follow, but rather to portray analytically those processes that we personally have found of help, and to open up the dialogue space (Smith et al., 2009) to a frank exchange of thoughts and ideas about how we actually 'do' sociologicalphenomenological research - and also qualitative research more generally.

\section{Acknowledgements}

We would like to thank all the swimmers who gave their time in participating in the study and the coaches for allowing such privileged access to their programme. 


\section{References}

Adler, P. and Adler, P., 1989. The gloried self: the aggrandisement and the constriction of the self. Social Psychology Quarterly, 52 (4), 299-310.

Ahern, K.J., 1999. Ten tips for reflexive bracketing. Qualitative Health Research, 9, 407411.

Allen-Collinson, J., 2009. Sporting embodiment: sports studies and the (continuing) promise of phenomenology. Qualitative Research in Sport \& Exercise, 1 (3), 279-296.

Allen-Collinson, J., 2011. Intention and epochē in tension: autophenomenography, bracketing and a novel approach to researching sporting embodiment. Qualitative Research in Sport, Exercise \& Health, 3 (1), 48-62.

Allen-Collinson, J., 2013 Autoethnography as the engagement of self/other, self/culture, self/politics, selves/futures. In: S. Holman Jones, T.E. Adams and C. Ellis, eds. Handbook of autoethnography. Walnut Creek, CA: Left Coast Press, 281-299.

Allen-Collinson, J. and Hockey, J., 2011. Feeling the way: notes toward a haptic phenomenology of scuba diving and distance running. International Review for the Sociology of Sport, 46 (3), 330-345.

Allen-Collinson, J. and Owton, H., 2015. Intense embodiment: senses of heat in women's running and boxing. Body \& Society, 21 (2), 245-268.

Allen-Collinson, J., Vaittinen, A., Jennings, G. and Owton, H., 2018. Exploring lived heat, 'temperature work' and embodiment: novel auto/ethnographic insights from physical cultures. Journal of Contemporary Ethnography, 47 (3), 283-305.

Ashworth, P., 1999. 'Bracketing' in phenomenology: renouncing assumptions in hearing about student cheating. Qualitative Studies in Education, 12 (6), 707-721.

Atkinson, M.F., 2017. Ethnoaesthesia: Ashtanga yoga and the sensuality of sweat. In: A.C. Sparkes, ed. Seeking the senses in physical cultures: sensual scholarship in action. London: Routledge, 42-62. 
Buscatto, M., 2016. Practising reflexivity in ethnography. In: D. Silverman, ed. Qualitative research. London, Sage, 137-151.

Chisholm, D., 2008. Climbing like a girl: an exemplary adventure in feminist phenomenology. Hypatia, 23 (1), 9-40.

Clegg, J.L. and Butryn, T.M., 2012. An existential phenomenological examination of parkour and freerunning. Qualitative Research in Sport, Exercise and Health, 4 (3), 320-340.

Crossley, N., 1995. Merleau-Ponty, the elusive body and carnal sociology. Body \& Society, $1(1), 43-63$.

de Beauvoir, S., 1972. The second sex, trans. H. Parshley. Harmondsworth: Penguin Books.

Dreyfus, H.L. and Rabinow, P., 1982. Michel Foucault: beyond structuralism and hermeneutics. Brighton: Harvester.

Evans, A. B. and Allen-Collinson, J., 2016. From 'just a swimmer' to a 'swimming mother': women's embodied experiences of recreational aquatic activity with pre-school children. Leisure Studies, 35 (2), 141-156.

Evans, A. B., Allen-Collinson, J. and Williams, R. K., 2017. Risky bodies, risky spaces, maternal 'instincts': swimming and motherhood. International Review for the Sociology of Sport, 52 (8), 872-991.

Evers, C., 2006. How to surf. Journal of Sport and Social Issues, 30 (3), 229-243.

Fisher, L. and Embree, L., eds. 2000. Feminist phenomenology. Dordrecht, Netherlands: Kluwer Academic Publishers.

Frank. A., 2005. What is dialogical research, and why should we do it? Qualitative Health Research 15, 964-974.

Fullagar, S., 2017. Post-qualitative inquiry and the new materialist turn: implications for sport, health and physical culture research. Qualitative Research in Sport, Exercise \& Health, 9 (2), 247-257. 
Garfinkel, H., 2002. Ethnomethodology's program: working out Durkheim's aphorism, ed. A. Warfield Rawls. New York: Rowman \& Littlefield.

Giorgi, A., 1997. The theory, practice, and evaluation of the phenomenological method as a qualitative research procedure. Journal of Phenomenological Psychology, 28, 235-261. Goffman, E., 1959. The presentation of self in everyday life. Harmondsworth: Penguin.

Hesse-Biber, S. N., 2016. The Oxford handbook of multimethod and mixed methods inquiry. Oxford: Oxford University Press.

Hesse-Biber, S. N. and Piatelli, D., 2012. The feminist practice of holistic reflexivity. In: S. N. Hesse-Biber, ed. The handbook of feminist research: theory and praxis (2nd ed.). Thousand Oaks, CA: SAGE.

Hochschild, A.R., 2003. The economy of gratitude. In: A.R. Hochschild, ed. The commercialization of intimate life. Berkeley: University of California Press.

Hockey, J. and Allen-Collinson, J., 2009. The sensorium at work: the sensory phenomenology of the working body, The Sociological Review, 57 (2), 217-239.

Howe, P.D., 2018. Athlete, anthropologist and advocate: moving towards a lifeworld where difference is celebrated. Sport in Society, 21 (4), 678-688.

Hughes, C., 2016. The senses, the self and the physically active body: a sensual ethnography of bouldering. Unpublished doctoral dissertation. Leeds: Leeds Beckett University.

Husserl, E., 1983. Ideas pertaining to a pure phenomenology and to a phenomenological philosophy, trans. F. Kersten. Dordrecht: Kluwer Academic Publishers.

Husserl, E., 1999. Cartesian meditations. an introduction to phenomenology, trans. D. Cairns. Dordrecht: Kluwer Academic Publishers.

Kerry, D.S. and Armour, K.M., 2000. Sport sciences and the promise of phenomenology: philosophy, method, and insight. Quest, 52 (1), 1-17. 
Kosma, M. and Buchanan, D.R., 2018. "Connect," log it, track it, go! Techné - not technology - and embodiment to achieve phronesis in exercise promotion. Quest, 70 (1), 100-113.

Kupers, W., 2005. Phenomenology and integral pheno-practice of embodied wellbe(com)ing in organizations. Culture and Organization, 11 (3), 221-232.

Kvale, S. and Brinkmann, S., 2009. InterViews: leaning the craft of qualitative research. Thousand Oaks, CA: SAGE.

Leder, D., 1990. The absent body. Chicago: University of Chicago Press.

Lund, O., Ravn, S., and Krogh Christensen, M., 2012. Learning by joining the rhythm: apprenticeship learning in elite double sculls rowing. Scandinavian Sport Studies Forum, 3, 167-188.

Mann, S.A. and Kelley, L.R., 1997. Standing at the crossroads of modernist thought: Collins, Smith, and the new feminist epistemologies. Gender \& Society, 11 (4), 391-408.

McMahon, J., Zehntner, C. and McGannon, K.R., 2017. Fleshy, female and forty: a docudrama of a former elite swimmer who re-immersed herself into elite swimming culture. Qualitative Research in Sport, Exercise and Health, 9 (5), 546-553.

Merleau-Ponty, M., 1969. The visible and the invisible, trans. A. Lingis. Evanston, IL: Northwestern University Press.

Merleau-Ponty, M., 2001. Phenomenology of perception, trans. C. Smith. London: Routledge \& Kegan Paul.

Owton, H. and Allen-Collinson, J., 2014. Close but not too close: friendship as method(ology) in ethnographic research encounters. Journal of Contemporary Ethnography, 43 (3), 283-305.

Parviainen, J. and Aromaa, J., 2017. Bodily knowledge beyond motor skills and physical fitness: a phenomenological description of knowledge formation in physical training. Sport, Education and Society, 22 (4): 477-492. 
Plummer, K. 2001. Documents of life 2: An invitation to a critical humanism. London: Sage.

Nesti, M., 2004. Existential psychology and sport. London: Routledge.

Purser, A., 2018. 'Getting it into the body': understanding skill acquisition through MerleauPonty and the embodied practice of dance. Qualitative Research in Sport, Exercise and Health, 10 (3), 318-332.

Ravn, S. and Høffding, S., 2016. The promise of 'sporting bodies' in phenomenological thinking - how exceptional cases of practice can contribute to develop foundational phenomenological concepts. Qualitative Research in Sport, Exercise and Health, 9 (1), $56-68$.

Schütz, A., 1967 Phenomenology of the social world, trans. G. Walsh and F. Lehnert. Evanston, IL: Northwestern University Press.

Shilling, C., 2017. Body pedagogics: embodiment, cognition and cultural transmission. Sociology, $51(6), 1205-1221$

Sparkes, A. C., and Smith, B., 2014. Qualitative research methods in sport, exercise and health: from process to product. Abingdon: Routledge.

Spencer, D. C., 2012. Ultimate fighting and embodiment: violence, gender and mixed martial arts. London: Routledge.

Smith, J., 2005. Merleau-Ponty and the phenomenological reduction. Inquiry: An Interdisciplinary Journal of Philosophy, 48 (6), 553-571.

Smith, B., Allen-Collinson, J., Phoenix, C., Brown, D. and Sparkes, A., 2009. Dialogue, monologue, and boundary crossing within research encounters: a performative narrative analysis. International Journal of Sport \& Exercise Psychology, 7 (3), 342359.

Sparkes, A.C., ed., 2017. Seeking the senses in physical cultures: sensual scholarship in action. London: Routledge. 
Stewart, D., and Mickunas, A., 1990. Exploring phenomenology: a guide to the field and its related literature. Athens: Ohio University Press.

Thorpe, H., and Olive, R. 2016. Conducting observations in sport and exercise settings. In: B. Smith and A. C. Sparkes, eds. Routledge handbook of qualitative research in sport and exercise. London: Routledge, 124-138.

Young, I.M., 1980. Throwing like a girl: a phenomenology of feminine body comportment, motility and spatiality. Human Studies, 3, 137-156.

Young, I.M., 1998. 'Throwing like a girl': twenty years later. In: D. Welton, ed. Body and flesh: a philosophical reader. Oxford: Blackwell, 286-290.

Vaittinen, A., 2014. Varieties of embodied knowing: an ethnographic study of Mixed Martial Arts. Unpublished doctoral dissertation. Newcastle: Newcastle University.

Wheaton, B., 2002. Babes on the beach, women in the surf: researching gender, power and difference in the windsurfing culture. In: J. Sugden and A. Tomlinson, eds. Power games: a critical sociology of sport. London: Routledge, 240-266.

Word count: 7971 